\title{
1 Spillover of an alien parasite reduces expression of costly behaviour in native host species
}

2 Francesca Santicchia ${ }^{1}$, Lucas A. Wauters ${ }^{1,2}$, Anna Pia Piscitelli ${ }^{3}$, Stefan Van Dongen ${ }^{2}$, Adriano

3 Martinoli $^{1}$, Damiano Preatoni ${ }^{1}$, Claudia Romeo ${ }^{4}$, Nicola Ferrari ${ }^{4}$

$4{ }^{1}$ Environment Analysis and Management Unit “Guido Tosi research group”, Department of Theoretical and Applied

5 Sciences, Università degli Studi dell’Insubria, Via J.H. Dunant 3, 21100 Varese, Italy; ${ }^{2}$ Department of Biology,

6 University of Antwerp, Universiteitsplein 1, 2610 Wilrijk, Belgium; ${ }^{3}$ Dipartimento di Biologia e Biotecnologie

7 “Charles Darwin”, Università “La Sapienza” di Roma, Viale dell’Università 32, 00185 Roma, Italy; ${ }^{4}$ Department of

8 Veterinary Sciences and Public Health, Università degli Studi di Milano, Via Celoria 10, 20133 Milano, Italy

10 Corresponding author: Lucas Wauters, Environment Analysis and Management Unit “Guido Tosi

11 research group”, Department of Theoretical and Applied Sciences, Università degli Studi

12 dell’Insubria, Via J.H. Dunant 3, 21100 Varese, Italy. Email: lucas.wauters@uninsubria.it 
1. Understanding effects of invasive alien species (IAS) on native host-parasite relationships is of importance for enhancing ecological theory and IAS management. When IAS and their parasite(s) invade a guild, the effects of interspecific resource competition and/or parasitemediated competition can alter existing native host-parasite relationships and the dependent biological traits such as native species’ behaviour.

2. We used a natural experiment of populations of native red squirrels (Sciurus vulgaris) that were colonised by the alien grey squirrel (Sciurus carolinensis), comparing repeated measurements of red squirrel parasite infection and personality with those taken in sites where only the native species occurred.

3. We explored two alternative hypotheses: (a) individual differences in personality traits (activity and/or sociability) of native red squirrel positively affect the probability of macroparasite spillover and thus the likelihood to acquire the alien's parasitic helminth (Strongyloides robustus); (b) the combined effects of grey squirrel presence and parasite infection result in a reduction of costly personality traits (activity and/or exploration).

4. Using data from 323 arena tests across three experimental (native species and IAS) and three control sites (only native species), we found negative correlations between native species’ activity and infection with $S$. robustus in the sites invaded by the alien species. Activity was also negatively correlated with infection by its native helminth (Trypanoxyuris sciuri) but only when grey squirrels were present, while in the red-only sites there was no relationship of $T$. sciuri infection with any of the personality traits. Moreover, individuals that acquired $S$. robustus during the study reduced their activity after infection, while this was not the case for animals that remained uninfected.

5. Our results show that parasite-mediated competition is costly, reducing activity in individuals of the native species, and altering the native host-native parasite relationships. 


\section{KEYWORDS}

41 Helminths, invasive alien species, macroparasites, Mirror Image Stimulation test, Open Field Test, personality traits, Sciurus carolinensis, Sciurus vulgaris

\section{INTRODUCTION}

Species interactions within a guild are often complex and interspecific competition can have implications for population dynamics, niche partitioning, prey-predator dynamics and host-parasite interactions (Sih, Cote, Evans, Fogarty, \& Pruitt, 2012; Henrichs et al., 2016; Rhoades, Best, \& Stachowicz, 2018). With the world-wide increase of biological invasions, a growing number of invasive alien species (IAS) and the parasites they carry can change or disrupt species interactions that were shaped by natural selection, including the existing host-parasite relationships (Hatcher et al., 2006; Sih et al., 2012; Ezenwa et al., 2016). When new (alien) parasites are transmitted to a susceptible naive native host species (parasite spillover, Power \& Mitchell, 2004) they can affect the new host's body condition, survival or reproductive success, and even behaviour. Furthermore, in their new range, invasive species can acquire local parasites. This can result in an extra cost to the IAS but the IAS can also act as reservoir, amplifying the transmission of parasites to the native species (parasite spill-back; Kelly, Paterson, Townsend, Poulin, \& Tompkins, 2009). These processes, where parasites mediate native/invader interactions, can play a key role in determining the outcome of invasions and are referred to as disease-mediated invasions (Strauss et al., 2012; Lymbery, Morine, Gholipour Kanani, Beatty, \& Morgan, 2014).

Animal personality, defined as consistent among-individual differences in behaviour (Réale, Reader, Sol, McDougall, \& Dingemanse, 2007; Carter, Feeney, Marshall, Cowlishaw, \& Heinsohn, 2013), can influence the probability to encounter infective stages, become infected and, 
subsequently, spread parasites (Kortet, Hedrick, \& Vainikka, 2010; Hawley, Etienne, Ezenwa, \& Jolles, 2011; Ezenwa et al., 2016). Hence, variation in individual personality can result in betweenindividual heterogeneities in parasite infection (VanderWaal \& Ezenwa, 2016). Conversely, parasites may influence the expression of behaviour and personality. Some parasites directly manipulate host behaviour to enhance their transmission (Poulin, 2013; Poirotte et al., 2016; Petkova, Abbey-Lee, \& Løvlie, 2018), while others induce physiological or immunological changes, which in turn can alter host behaviour (Kortet et al., 2010; Barber \& Dingemanse, 2010; Poulin, 2013). In summary, the interactions between parasites and host behaviour or personality traits, in particular boldness, activity-exploration or sociability, are complex and parasite transmission can occur not only between individuals of the same species, but also from one species to another, potentially influencing the mechanisms of interspecific competition.

Here, we use the well-known case of native - alien species competition between the Eurasian red squirrel (Sciurus vulgaris) and the introduced invasive North American grey squirrel (Sciurus carolinensis) in Europe to explore the relationships between the native host's personality and infection by both native and alien (acquired) macroparasites. The two species have similar space use and activity patterns, and compete for limited food resources (interspecific resource competition, hereinafter IRC), resulting in smaller body size, and reduced female reproduction and juvenile recruitment in red squirrels (Wauters, Tosi, \& Gurnell, 2002a; Wauters, Gurnell, Martinoli, \& Tosi, 2002b; Gurnell et al., 2004), ultimately causing a decrease in population size and (local) extinction (Bertolino, Montezemolo, Preatoni, Wauters, \& Martinoli, 2014). Furthermore, in areas where the two species compete, red squirrels had higher sociability scores than in areas without the alien species (Wauters et al., 2019). In the natural situation (only red squirrels present), the gastrointestinal macroparasite fauna of red squirrels is dominated by a single species, the pinworm Trypanoxyuris sciuri (Romeo et al., 2013; Santicchia et al., 2015). This species is an oxyurid nematode with direct faecal-oral transmission: eggs are deposited on the perianal region and ingested during grooming. Vertical transmission can occur from females to their young in the nest, 
while horizontal transmission through physical contact or environmental contamination is considered rare (Anderson, 2000). Because of this mainly vertical transmission and since oxyurids tend to be low pathogenic (Anderson, 2000), we predict that there will be no relationship between a red squirrel's personality, considering the traits activity, exploration or sociability, and T. sciuri infection status (being infected or not). In contrast with the natural situation, in woodlands colonised by grey squirrels, spillover of the grey squirrel's common helminth, Strongyloides robustus, from the alien to the native species occurs with about $61 \%$ of red squirrels infected by the alien nematode (Romeo al., 2014a, 2015). This helminth’s eggs are shed with host faeces in the environment where they hatch, the larvae undergo two moults until the infective stage (L3 larvae) penetrates the skin of a new host, and migrates towards the GI tract. Consequently, the probability of acquiring $S$. robustus will depend on the exposure to these free-living infective stages (Romeo et al., 2014a, 2015). Therefore, we predict that infection risk toward the invasive parasite should be higher for individuals with a more active (considered to forage and/or move more intensively), explorative (move over longer distances visiting more often areas outside their core-area) or social personality (use habitat patches shared by more animals), than for red squirrels that are less active or explorative and less social, since these individuals will move less, over shorter distances and avoid patches of high squirrel density and contact with other squirrels (Wauters \& Dhondt, 1989, 1992; Wauters et al., 2019).

Here, we explore two non mutually exclusive hypotheses. (1) Based on the role of the host's behaviour on the parasites' life cycles described above, we test the hypothesis that the personality traits of the native species, activity, exploration tendency and sociability, positively affect parasite infection by the alien helminth S. robustus in sites colonised by grey squirrels, but that there is no relationship between these traits and infection by the common native parasite $T$. sciuri. (2) Since parasites can also induce physiological changes in their hosts, which in turn can alter host behaviour or personality (e.g. Poulin, 2013; Ezenwa et al., 2016), we also consider that macroparasite 
114 infection induces energetic costs of specific behaviours or personality traits, such as activity and/or exploration (Hicks et al., 2018), negatively affecting their expression. To test these hypotheses, we determined whether native red squirrels were infected by the dominant native gastrointestinal helminth (T. sciuri) and/or by the alien helminth (S. robustus), acquired through spillover from its original host, the grey squirrel (Romeo et al., 2014a, 2015), and used 323 arena tests across three experimental (native species and IAS, $\mathrm{n}=152$ tests of 79 individuals) and three control sites (only native species, $\mathrm{n}=171$ tests of 105 individuals) to quantify host personality and parasite infection status.

\section{MATERIALS AND METHODS}

\subsection{Study sites and trapping squirrels}

We trapped and monitored squirrels in three red-only sites and in three red-grey sites with comparable habitat quality (availability of preferred tree-seeds) and squirrel densities (see Supporting Information S1 and Table S1) (see also Wauters et al., 2019). Trapping was carried out in two to four periods per year between January 2016 and December 2018 (Supporting Information Table S1 for details). We used Tomahawk “squirrel” traps (models 201 and 202, Tomahawk Live Trap, WI, USA), placed on the ground or at breast height against tree trunks, that were more or less homogeneously distributed over the study site. Trap densities varied among sites in relation to expected squirrel density (see also Supporting Information Table S1). We pre-baited traps with hazelnuts 3 to 4 times over a 30 day period, then baited and set for 4-5 days. We checked traps two to three times per day to reduce the time a squirrel was restrained inside a trap. Each trapped red squirrel was flushed into a light cotton handling bag (zipper tube) to minimize stress during handling, and individually marked using numbered metal ear-tags (type 1003 S, National Band and Tag, Newport, KY, USA). It was weighed to the nearest $5 \mathrm{~g}$ using a spring-balance (Pesola AG, 
Baar, Switzerland) and the length of the right hind foot, a reliable proxy for a squirrel's body size used in most studies, was measured with a thin ruler $( \pm 0.5 \mathrm{~mm})$ (Wauters et al., 2007). Sex, age class and reproductive condition were determined from external genitalia and body mass, with juvenile red squirrels weighing less than $250 \mathrm{~g}$ (Wauters \& Dhondt, 1989). We applied adhesive tape tests on the perianal region to determine presence/absence of T. sciuri since this is a more reliable method than coprological analysis for oxyurid egg detection (Foreyt, 2011). To detect $S$. robustus eggs, we collected fresh faecal samples from the trap floor (which was cleaned after each capture event) which were stored dry at $4{ }^{\circ} \mathrm{C}$ for later examination. We carried out coprological analyses within 3 days from sample collection to avoid egg hatching.

In the experimental sites (red-grey sites), we removed grey squirrels as part of a red squirrel conservation project. We euthanized animals by $\mathrm{CO}_{2}$ inhalation, following the EC and AVMA guidelines (Santicchia et al., 2018). Doing so, we kept grey squirrel densities controlled to guarantee persistency of red squirrels in the experimental sites (see also Santicchia et al., 2018).

\subsection{Parasite and personality measures}

We examined tape test slides under a microscope $(\times 40$ or $\times 100$ magnification $)$ to determine red squirrels' infection status by $T$. sciuri $(1=$ infected, $0=$ not infected $)$. We analysed faecal samples quantitatively with McMaster technique and qualitatively with flotation to determine S. robustus intensity of infection (faecal egg count, FEC) and infection status (presence/absence; Romeo et al., 2014b, 2015) (details of these methods in Supporting Information S2). The FEC method is commonly used to infer intensity of infection on living hosts (Patterson \& Schulte-Hostedde, 2011; Romeo et al., 2014b), although FEC values are not always linearly related to actual worm burdens. Romeo et al. (2014b) demonstrated that for grey squirrels, the typical host of $S$. robustus, there was a significant curvilinear relationship between the number of adult worms and FEC due to 
suppression of helminth fecundity related to the activation of the host immune response (Paterson \& Viney, 2002).

After checking a red squirrel's identity, we released it inside the arena by opening a sliding door (28 $\times 15 \mathrm{~cm}$, internal opening $12 \times 12 \mathrm{~cm}$ ), allowing the animal to move from the handling bag into the arena (Mazzamuto et al., 2018). Arena tests consisted of an Open Field Test (OFT) followed by a Mirror Image Stimulation test (MIS) that were carried out as described elsewhere (Mazzamuto et al., 2018; Wauters et al., 2019; details in Supporting Information S2). For each experiment we calculated the time that individuals spent in each behavioural state using the CowLog 3.0.2 software (Hänninen \& Pastell, 2009). Ethogram description and procedures to define the expert-based (EB) personality traits as in Mazzamuto et al. (2018) and Wauters et al. (2019) (for details see Supporting Information S2 and Table S2). Applying Factor Analysis (FA) instead of the expert-based approach did not change our results. All data handling and analysis carried out with R (R Core Team 2019). To check the assumptions of repeatability of personality traits we repeated both experiments (OFT and MIS) in different capture-sessions to have at least two arena tests for most individuals. The minimum time between tests for the same individual was 12 days (mean $\pm \mathrm{SE}=85 \pm 7$, range: 12734 days).

\subsection{Data handling and statistical analyses}

We obtained scores for seven personality traits (Supporting Information Table S2): activity, exploration and shyness from OFT; sociability, avoidance, alert and other (the latter a combination of activity and exploration; Mazzamuto et al., 2018) from MIS. Scores were squareroot transformed before analyses to meet assumptions of normality. Exploratory data analyses revealed that sociability and avoidance were strongly, negatively correlated (Pearson correlation coefficient $r=$ 0.89) and had a non-normal error distribution that made it difficult to be fitted in a multivariate 
MCMCglmm. Therefore, we calculated a new variable that measured the sociability-avoidance continuum (hence the tendency to react more or less social or amenable to the mirror image) with the formula:

Social tendency = log-transformed [(sociability score + (1-avoidance score) $) / 2]$

Since the definition of personality implies that the measured behaviour must have consistent between-individual variation over time and under different contexts (e.g. Réale et al., 2007; Carter et al., 2013), we first estimated the repeatability of the expert-based traits (on all data of both redonly and red-grey sites) as the between-individual variation divided by the sum of the betweenindividual and residual variation, using Bayesian generalized linear mixed effects models based on a Markov Chain Monte Carlo algorithm with the R package MCMCgImm version 2.26 (Hadfield, 2010). Each model had a personality trait as dependent variable and study site, sex, arena test order (from 1 to a maximum of 6 tests) and year as fixed effects, and squirrel identity as random effect. Posterior distributions were based on 1050000 iterations with a burnin of 50000 iterations and thinning of 40, such that 25000 iterations were used to obtain point estimates and 95\% credibility intervals. For the random effects and residual variation an inverse-gamma prior uninformative for the model was used (Wilson et al., 2010). We found moderate repeatabilities (Table 1, R $>0.20$; see also Bell et al., 2009) for activity from OFT and for social tendency and activity-exploration score from MIS (details in Supporting Information Table S2 and Table S3), which were further used as personality traits in the MCMCglmm models below.

\subsubsection{MCMCglmm models on parasite infection status - personality relationships}

Since we were interested in testing possible interactions of area-type (red-only vs. red-grey) on the personality - parasite relationships, we performed two multivariate MCMCglmm models, one for each area-type. All data were used for each area-type, hence sample sizes are 171 for 105 
individuals in red-only, and 152 for 79 individuals in red-grey area-type. In the red-only model, the personality traits (activity, social tendency and activity-exploration, see Table 1) and infection status by $T$. sciuri were the dependent variables. In the red-grey model, the same personality traits, and infection status by $T$. sciuri and by S. robustus were the dependent variables. We then tested explicitly for any differences in the various correlations between personality traits and T. sciuri infection between the area-types by comparing the slopes of the posterior distributions from the two separate models.

The expert-based personality traits (activity, social tendency and activity-exploration) were treated as dependent variables after centering and scaling $\left[\left(x_{i}-\right.\right.$ mean $\left.\left.x\right) / S D x\right]$ with a Gaussian residual error distribution, while T. sciuri and S. robustus infections were treated as binomial dependent variables (0 not infected, 1 infected). Assumption of normality of the personality traits was supported by their QQ-plots. In addition, sex, body mass, year and arena test order were added as fixed effects; the latter accounted for possible habituation effects. We did not include pregnant females to avoid a bias due to extra weight of developing embryos. In both models, the effect of arena test order was set to zero for T. sciuri and S. robustus infection. As repeated observations were present, individual was added as a random effect. Also study site was added as random effect (as a heterogeneous identity matrix) to avoid pseudoreplication problems during the parameter estimation process. For both the residual and between-individual variation, an unstructured variancecovariance matrix was modelled, allowing the estimation of correlations among the dependent variables (covariance divided by the square root of the product of the variances). Posterior distributions were based on 1050000 iterations with a burnin of 50000 iterations and thinning of 40, such that 25000 iterations were used to obtain point estimates and 95\% credibility intervals. For all

232 fixed effects related parameters (i.e., intercept, slopes, differences), the prior distribution was 233 Gaussian with zero mean and variance equal to $10^{8}$ (default setting in MCMCglmm). For the 234 random effects and residual variation and inverse Wishard prior was set with diagonal elements 
equal to $0.5,0.5$ and 0.1 for the residual (i.e., within-individual variation), between-individual and nested study site effect respectively. The believe parameter was set to 0.01 . We applied the GelmanRubin statistic (Gelman \& Rubin, 1992) and Geweke diagnostic (Geweke, 1992) which confirmed model consistency and convergence. Full model outputs are provided in Supporting Information, Table S4 and S5.

\subsubsection{GLMM on changes $S$. robustus infection status and changes in activity}

In the red-grey area-type, we had two consecutive measures of the activity score from OFT for a subset of 24 samples. In 14 cases the squirrels changed from a status of non-infected to infected by

S. robustus (group 1). In the other 10 cases, the animal remained non-infected both at first and second measure of activity (group 2). If becoming infected was the cause for the decrease in activity expression observed in the MCMCglmm model (see results), we predict a significant decrease in activity scores in group 1 [hence a negative value for the difference between the second (infected) minus first (non-infected) activity measure], but no difference between second and first measure in group 2. We used a GLMM with the difference in amount of activity between second and first measure as dependent variable (hereinafter $\Delta$ activity), and group as fixed effect. We added arena test order (first or subsequent), sex and T. sciuri infection status as potentially confounding factors, and squirrel id as random effect since three individuals were used twice (occurred once in group 1 and once in group 2). We used a stepwise backward model selection, removing the non-significant (partial $\mathrm{p}>0.10$ ) fixed effects.

\subsubsection{GLMM on activity - intensity of infection by S. robustus}

FEC were obtained from 62 samples of 43 individual red squirrels for which we also had measures of personality traits. This sample size proved too small to run multivariate models as above and 
resulted in convergence problems in an overparametrized model. We therefore, used centered and scaled activity scores as response variable in a GLMM to explore whether activity (the only trait significantly related to infection status, see Results) decreased with intensity of infection by $S$. robustus. FEC values were centered and scaled after Log FEC transformation and used as fixed effect. We added infection status of $T$. sciuri, squirrel sex, body mass and arena test order (first vs subsequent tests) as fixed effects and the interaction of FEC by T. sciuri infection status to account for a potential effect of multi-species infection. Squirrel id and study sites were added as random effects to avoid pseudoreplication problems during the parameter estimation and significance testing.

\section{RESULTS}

\subsection{Grey squirrel presence and parasite infection}

271 In red-only sites, 116 on 171 tape tests were positive for $T$. sciuri (estimate $\pm S E=68 \pm 4 \%$ ) against

272113 on $152(74 \pm 4 \%$ ) in red-grey sites. Prevalence of infection (an individual was scored as 273 infected when at least one test was positive) by $T$. sciuri was $69 \pm 4 \%$ (72 on 105 red squirrels) in 274 red-only sites and $78 \pm 5 \%$ (62 on 79 individuals) in red-grey sites. The alien parasite, S. robustus, 275 was not found in red-only sites, whereas in the red-grey sites, 95 on 152 (63 \pm 4\%) faecal samples were positive for its eggs, for a prevalence of $75 \pm 5 \%$ (59 on 79 individuals). In the red-grey sites, 277138 out of 152 samples (91 $\pm 7 \%$ ) had at least one parasite species; of these 43 were positive only 278 for $T$. sciuri (28 $\pm 4 \%$ ), 25 only for S. robustus (17 $\pm 3 \%$ ) while 70 (46 $\pm 4 \%)$ were from red squirrels infected by both $S$. robustus and native T. sciuri. Faecal egg counts (FEC) varied from 1 to 945 ( $n=62$; median 53; 25-75\% quartiles $9-316$ ). On average (mean $\pm S E$ ), an infected red squirrel had $201 \pm 36$ S. robustus eggs in the McMaster slide. 


\subsection{Personality and parasitism}

284 We explored effects of a squirrel's sex and body mass, and of year and arena test order on the traits activity, social tendency and activity-exploration and on infection status of T. sciuri (both areatypes) and of $S$. robustus (only red-grey) infection status.

In the red-only sites, there were strong and positive correlations between the three personality traits, suggesting a behavioural syndrome of more active-explorative squirrels being also more social (Table 2, all $r>0.85$ ). The correlations of activity, activity-exploration or social tendency with $T$. sciuri infection were not significant (Table 2), indicating that a red squirrel's personality was not related with the probability of infection with $T$. sciuri in red-only sites. Among the relationships between the fixed effects and the dependent variables, the traits activity-exploration and social tendency were expressed more strongly in 2017 and 2018 than in 2016 while in 2018 fewer red squirrels were infected by T. sciuri than in 2016 (Supporting Information Table S4).

In the red-grey sites, the correlation between the traits activity and activity-exploration was significant (Table 2). In contrast with the red-only sites, there was a significant but negative correlation between $T$. sciuri infection and activity, but no such relationship was found with the other two traits (Table 2). Similarly, expression of activity was also negatively correlated with $S$. robustus infection status, while the relationships of probability of infection by S. robustus with the other two traits was not significant (Table 2). The probabilities of being infected by T. sciuri and by S. robustus were not correlated suggesting that there was no significant tendency for red squirrels that were infected by $T$. sciuri to be infected also by S. robustus ( $r=0.53,95 \% C I=-0.19$ to 1.00 ; Table 2). Among the fixed effects, sex affected social tendency and probability of infection by $S$. robustus: males tended to behave less social, and were also less infected with $S$. robustus than females (Supporting Information Table S5). Activity was expressed more strongly in 2017 than in 2016 and had lowest values in 2018 (Supporting Information Table S5). 


\subsection{Changes in $S$. robustus infection and in activity}

On the subset of 24 samples with consecutive measures of activity scores, 14 changed from being non-infected to infected by S. robustus (group 1, see methods), while 10 were non-infected at both measures (group 2). The effects of arena test order $\left(\mathrm{t}_{19}=0.59 ; \mathrm{p}=0.59\right)$, . sciuri infection status $\left(\mathrm{t}_{20}=1.39 ; \mathrm{p}=0.18\right)$ and $\operatorname{sex}\left(\mathrm{t}_{21}=1.50 ; \mathrm{p}=0.15\right)$ on $\Delta$ activity were not significant and removed during stepwise model selection. The $\Delta$ activity in group 1 was negative and significantly different from that in group $2(\Delta$ activity group 1 , mean $\pm \mathrm{SE}=-0.182 \pm 0.049 ; \Delta$ activity group 2 , mean $\pm \mathrm{SE}$ $=0.009 \pm 0.083$; group effect: $\left.t_{22}=2.22 ; \mathrm{p}=0.037\right)$. Thus, red squirrels in group 1 showed $\mathrm{a}$ significant decrease in activity from non-infected to infected by $S$. robustus while there was no difference between second and first measure in group 2 (Fig. 1; for individual changes in activity see Fig S1a, b in Supporting Information), suggesting that becoming infected by S. robustus was the cause for the observed negative correlation between activity and S. robustus infection in the global MCMCglmm model.

\subsection{Expression of activity and intensity of $S$. robustus infection estimated by FEC}

Since in the MCMCglmm models above, only activity of red squirrels was related with S. robustus infection status, we only analysed activity as dependent variable. Red squirrels expressed more activity in the first (22 samples) than in subsequent (40 samples) arena tests (estimate $0.79 \pm 0.23$; $\left.t_{55}=3.46 ; p=0.001\right)$ and there was a significant FEC by $T$. sciuri infection status interaction $(-0.59$ $\left.\pm 0.26 ; t_{55}=2.26 ; p=0.028\right)$. Effects of sex and body mass were not significant (partial $\left.p>0.30\right)$ and removed from the model. To allow interpretation of the interaction, we tested relationships between FEC and activity, correcting for the arena test order effect, for animals infected by T. sciuri (44 cases) and not infected by T. sciuri (18 cases) separately. When already infected with their native parasite, red squirrels showed lower activity with increased shedding of S. robustus eggs (- 
$0.35 \pm 0.12 ; t_{41}=2.86 ; p=0.007 ;$ Fig $\left.2 a\right)$. In contrast, when they were not infected by T. sciuri, there was no relationship between their activity and $S$. robustus egg shedding $\left(0.21 \pm 0.22 ; t_{15}=\right.$ 0.94; $p=0.36$; Fig. 2b).

\section{DISCUSSION}

Relationships between host behaviour and/or personality and infection by native parasites have been widely studied (Barber \& Dingemanse, 2010; Poulin, 2013; Ezenwa et al., 2016). In contrast, studies on the role of invasive parasites on native hosts or native species communities, have focussed on highly pathogenic parasite species, often microparasites, and their role in influencing disease outbreaks in the invaded ecosystem and/or native species (Tompkins et al., 2002; Goedknegt et al., 2016). For example, a paradigm of disease-mediation invasions is the red-grey squirrel in Great Britain, with spillover of squirrelpox virus (SQPV) of the alien to the native squirrel. Grey squirrels are apparently unaffected by the infection, while infected red squirrels have extremely high mortality rates (Tompkins et al., 2002; Fiegna et al., 2016): hence the virus facilitates replacement of native red by alien grey squirrels (Tompkins, White \& Boots, 2003). In contrast with most microparasites, the majority of macroparasites have more subtle, non-lethal effects on their hosts, that may include changes in behaviour and/or energy allocation (Anderson \& May, 1979; Mathot \& Dingemanse, 2015; Hicks et al., 2018).

Here we investigated, to our knowledge for the first time, relationships of both native and alien macroparasites, the latter acquired through spillover, with potential changes in the behaviour or personality of the native host. Through a large-scale field study conducted in North Italy, we found that relationships of personality traits of native red squirrels with macroparasite infections differed between red-only sites and sites colonised also by the alien grey squirrel (red-grey sites). In the former, there was no relationship between red squirrel activity and T. sciuri (its common helminth) 
infection, while in red-grey sites, infection of red squirrels by $T$. sciuri and by $S$. robustus, an alien helminth acquired through parasite spillover from grey squirrels, was negatively correlated with host activity. Moreover, in the red-grey sites, individuals that changed infection status (from noninfected to infected) of S. robustus reduced activity after becoming infected, while no such trend was observed among red squirrels that remained uninfected.

\subsection{Interactions between host personality and native macroparasite infection}

Measuring personality traits and macroparasite infection of native red squirrels in (control) study sites without alien competitors or alien parasites and in (experimental) study sites that were colonised by alien grey squirrels carrying the alien helminth $S$. robustus, allowed us to investigate potential changes in native host - parasite relationships caused by parasite spillover. In the red-only sites, there was no relationship between a red squirrel's activity, exploration tendency or social tendency and T. sciuri infection status, confirming our first prediction which was based on this oxyurid’s transmission route characterised mainly by direct and vertical (mother - young) transmission. However, where native squirrels co-occurred with alien squirrels, the infection status of $T$. sciuri was negatively correlated with the expression of the personality trait activity; in other words, red squirrels infected by T. sciuri had lower activity than non-infected animals. This difference of the correlations of activity with T. sciuri infection between the red-only and the redgrey sites was significant, and suggests a cost to red squirrels of being infected with their common gastrointestinal helminth, but only when their woodland has been invaded by grey squirrels.

We can only give a tentative explanation of possible pathways that can explain this trend. In the redgrey sites, grey squirrels have been found to act as a stressor on co-occurring red squirrels, increasing the concentration of glucocorticoids (stress hormones) in individuals of the native species (Santicchia et al., 2018). One of the effects of long-term increased glucocorticoid levels

382 (chronic stress) is a suppression of the immune system (decrease in immune efficiency, e.g. 
Romero, 2004) which could, in our case, reduce the red squirrel's immune response to contrast $T$. sciuri infection. In general, oxyurid infections tend to be low pathogenic and without overt symptoms. However, heavy pinworm burdens might negatively affect the intestinal structure and/or function (Taffs, 1976) and the humoral or cell-mediated immune response is essential for maintaining the host-oxyurid parasite equilibrium (e.g. lab mice, Taffs, 1976; primates, Sorci et al., 2003). An alternative, but not mutually exclusive, explanation for the negative relationship between T. sciuri infection status and amount of activity in experimental sites could be a worse nutritional status, inducing either a higher host susceptibility to parasite infection or a reduced capability to cope with it. However, despite the habitat differences between control and experimental sites, they were of comparable quality in terms of availability of high-energy food resources (see Supporting Information S1 and Table S1). Moreover, previous studies did not reveal differences in prevalence or in intensity of infection by T. sciuri between conifer and deciduous woods (Santicchia et al., 2015). Hence, our results suggest that in sites invaded by grey squirrels, the typical equilibrium that exists between red squirrels and oxyurid infection is disrupted, possibly though a less efficient immune response that might be related directly to increased physiological stress caused by the occurrence of the alien squirrel or, indirectly, to the spillover of the alien parasite S. robustus. Indeed, previous research highlighted a significant increase in T. sciuri prevalence in areas coinhabited by grey squirrels, suggesting a reduced capability of the native species of coping with its native infection (Romeo et al., 2015).

\subsection{Effects of $S$. robustus spillover}

In the red-grey sites, we found a negative correlation between expression of activity by red squirrels and their infection status with the alien nematode S. robustus. Hence, infected animals showed lower activity during OFT than non-infected ones. These data support our second hypothesis that 
infection by the alien macroparasite induces energetic costs of specific behaviours or personality traits, in this case activity, negatively affecting its expression. However, we did not find a significant correlation between activity-exploration measured in the arena with S. robustus infection: the trend was negative, but credibility intervals were large and included 0 . This could be related to squirrels having low amounts of exploration behaviours (head dip, sniff and scratch, Table S2) in the arena test, and/or a poor agreement between the energetic costs of this trait as measured in the arena and exploration in a natural environment.

415 We have three lines of concurring evidence that suggest an influence of the alien parasite on the expression of the personality trait activity among the red squirrels occurring in study sites colonised by invasive grey squirrels (red-grey sites). First and foremost, we found a significant negative correlation between S. robustus infection status and amount of activity. Second, the directionality of this result (parasite infection causes reduction in expression of a personality trait) was confirmed by a subset of data where activity expression was reduced in animals tested both before and after infection by S. robustus, but not in a control group of squirrels that remained uninfected in each of

422 the two tests (Fig. 1). Third, among red squirrels infected by both T. sciuri and S. robustus, higher 423 intensity of infection by the alien nematode reduced activity more strongly than low infections. This 424 relationship was not found among animals not infected by their common endoparasite $T$. sciuri. The latter result suggests a cumulative effect of parasite coinfections (e.g. Fenton, Viney \& Lello, 2010; Ezenwa, 2016; Rothenburger et al., 2019) and that multi-species infections of native and alien

427 parasites could exacerbate the effects of each parasite species on host behaviour or personality. This might be especially true for those host species which have a naturally poor parasite community in terms of species richness and which, therefore, may be less capable of coping with multiple infections. This is the case of red squirrels, that are rarely infected by gastro-intestinal parasites

431 other than T. sciuri and a few coccidian protozoan (Romeo et al., 2013, Hoffmannova et al., 2016).

432 Finally, similarly to a previous study (Romeo et al., 2015), we found no significant association 
between $T$. sciuri and S. robustus infection, indicating that co-infection by the other parasite had no effect on the probability of infection of red squirrels by either of the two helminths.

We admit that we did not have direct measures of intensity of infection (worm counts in the intestine), but used the McMaster count of the number of $S$. robustus eggs expelled with the host's faeces (FEC). Despite this caveat, low and high FEC values are likely a good index of, respectively, low and high worm burdens. Moreover, FEC from red squirrels in this study suggest higher intensities of infection by S. robustus than in the original host (this study from 1 to 945 eggs, mean $440 \pm S E=201 \pm 36$; grey squirrels in Romeo et al., 2014b from 1 to 55; and in Romeo et al. submitted 441 from 1 to 43). This data strongly suggests a lower capability of the naive host of responding, and controlling, S. robustus infection.

\subsection{Critical considerations on directionality of host personality - parasite infection} relationships

Our two non-mutually exclusive hypotheses (personality affects parasite infection vs. parasite infection affects personality expression) are based on the direction (positive vs negative, respectively) of the correlations among the dependent variables in the multivariate MCMCglmm models. Hence, one could argue that the negative correlations of the amount of activity expressed during OFT and the infection status of $T$. sciuri and $S$. robustus is caused by low activity increasing the probability of becoming infected by each of the two helminths. There are several reasons why this is extremely unlikely. First, it is hard to find a biological explanation of how low activity could increase the likelihood of encountering infective stages of either parasite. Indeed, other studies on rodents addressing host personality - parasite relationships found positive effects of activity, exploration and/or boldness on infection by ecto- or endoparasites. In eastern chipmunks (Tamias 
striatus), bolder males had higher endoparasite loads than shy ones (Paterson \& Schulte-Hostedde,

458 2011), while in least chipmunks (Tamias minimus), more explorative animals hosted a greater

459 abundance of ectoparasites compared to less exploratory individuals (Bohn et al., 2017). Finally, in

460 the native grey squirrel host, probability of infection by $S$. robustus was higher for bolder, more

461 explorative individuals than shy, less explorative ones (Santicchia et al., 2019). However, since all

462 these studies are correlational, caution is needed with the interpretation of the direction of the

463 relationships. Boyer et al. (2010) tried to address directionality using path analysis, a statistical

464 approach, while an experimentally induced infection with a brain trematode (Diplostomum phoxini)

465 was used in a study on Eurasian minnows (Phoxinus phoxinus) (Kekäläinen et al., 2014).

466 Second, if low activity increased the probability of infection by T. sciuri, it should do so

467 independently of the presence of grey squirrels, but this pattern was not supported by our data that

468 showed a lack of correlation between activity and T. sciuri infection in the red-only sites. Third, this

469 hypothesis cannot explain the significant decrease in within-individual expression of activity

470 observed in the subset of red squirrels that became infected by the alien parasite between

471 consecutive arena tests; a decrease not observed among animals that remained uninfected. As

472 already mentioned above, this is the strongest result - although on a small sample - that it is indeed

473 becoming infected with $S$. robustus that drives the reduction in activity and not vice versa. Fourth,

474 the fact that also intensity of infection by S. robustus negatively affects the amount of activity expressed, but only among red squirrels co-infected by both helminths, confirms that infection by

476 an alien parasite is costly to the naive native host and causes red squirrels to reduce behaviours or

477 traits (in our case activity) that require high energy expenditure.

\section{$479 \quad 4.4$ Conclusions}

481 As predicted based on its typical oxyurid life-cycle with mainly direct transmission, we found no 482 relationship of the personality traits activity, activity-exploration tendency, or social tendency of red 
squirrels with $T$. sciuri infection status under natural conditions (in sites without the alien species).

This pattern changed in sites colonised by the alien competitor (red-grey sites) where infection with T. sciuri reduced the expression of the trait activity, but not of the other two traits. Likewise, spillover of the alien helminth $S$. robustus from grey squirrels to native red squirrels reduced the amount of activity expressed by the latter and this was confirmed by comparing levels of activity of animals that were tested before and after infection by $S$. robustus. Finally, also intensity of infection by $S$. robustus, estimated by faecal egg counts, was negatively related to the expression of activity, but only in the case of co-infection with both helminths. These results strongly suggest that infection by the alien parasite is costly to the naive native host species, in particular when individuals are already infected by a common helminth, and is indeed the causal factor behind the reduction of energetically costly personality traits, such as activity.

\section{ACKNOWLEDGEMENTS}

We thank Regione Lombardia, Città Metropolitana di Torino, Stelvio National Park, natural reserve - sic/zps "Bosco WWF di Vanzago", and the owners of private estates for permits and access to the study sites. We also thank a number of dedicated field technicians and thesis students for helping with data collection. Constructive comments by the associate editor and two reviewers greatly helped to improve the paper. This is paper number 31 of Alpine Squirrel Population Ecology Research (ASPER).

\section{AUTHORS' CONTRIBUTIONS}

FS, LAW, NF and AM developed the hypotheses and study design. LAW, APP and CR collected data, SVD, DP and FS analysed output data, LAW and FS led the writing of the manuscript. All authors contributed critically to the drafts and gave final approval for publication. 
509 We confirm that, should the manuscript be accepted, the data supporting the results will be archived 510 in an appropriate public repository (zenodo) and the data DOI will be reported at the end of the 511 article.

\section{REFERENCES}

514 Anderson, R.C. (2000). Nematode parasites of vertebrates: their development and transmission (2nd ed.). Wallingford, UK: CABI Publishing.

Anderson, R.C., \& May, R. (1979). Population biology of infectious diseases: Part I. Nature, 280, 361-367. doi:10.1038/280361a0

Barber, I., \& Dingemanse, N. J. (2010). Parasitism and the evolutionary ecology of animal personality. Philosophical Transactions of the Royal Society B: Biological Sciences, 365, 40774088. doi:10.1098/rstb.2010.0182

Bell, A. M., Hankinson, S. J., \& Laskowski, K. L. (2009). The repeatability of behaviour: a metaanalysis. Animal Behaviour, 77, 771-783. doi:10.1016/j.anbehav.2008.12.022

523 Bertolino, S., Montezemolo, N. C., Preatoni, D. G., Wauters, L. A., \& Martinoli, A. (2014). A grey 524 future for Europe: Sciurus carolinensis is replacing native red squirrels in Italy. Biological 525 Invasions, 16, 53-62. doi:10.1007/s10530-013-0502-3

526 Bohn, S.J., Webber, Q.M.R., Florko, K.R.N., Paslawski, K.R., Peterson, A.M., Piche, J.E., Menzies, 527 A.K., \& Willis, C.K.R. (2017). Personality predicts ectoparasite abundance in an asocial sciurid. 528 Ethology, 123, 761-771. doi: 10.1111/eth.12651.

529 Boyer, N., Réale, D., Marmet, J., Pisanu, B., \& Chapuis J-L. (2010) Personality, space use and tick 
530 load in an introduced population of Siberian chipmunks Tamias sibiricus. Journal of Animal 531 Ecology, 79, 538-547.

532 Brehm, A.M., Mortelliti, A., Maynard, G.A., \& Zydlewski J. (2019). Land-use change and the 533 ecological consequences of personality in small mammals. Ecology Letters, doi: 10.1111/ele.13324

534 Carter, A. J., Feeney, W. E., Marshall, H. H., Cowlishaw, G., \& Heinsohn, R. (2013). Animal 535 personality: what are behavioural ecologists measuring? Biological Reviews, 88, 465-475. 536 doi:10.1111/brv.12007

537 Ezenwa, V.O. (2016). Helminth-microparasite co

538 rodents and rabbits. Parasite Immunology, 38, 527-534. doi.org/10.1111/pim.12348

539 Ezenwa, V. O., Archie, E. A., Craft, M. E., Hawley, D. M., Martin, L. B., Moore, J., \& White, L. 540 (2016). Host behaviour-parasite feedback: an essential link between animal behaviour and disease 541 ecology. Proceedings of the Royal Society of London B: Biological Sciences, 283, 2015-3078. 542 doi:10.1098/rspb.2015.3078

543 Fenton, A., Viney, M.E., \& Lello J. (2010). Detecting interspecific macroparasite interactions from 544 ecological data: patterns and process. Ecology Letters, 13, 606-615. doi: 10.1111/j.1461545 0248.2010.01458.x

546 Fiegna, C., Dagleish, M.P., Coulter, L., Milne, E., Meredith, A., Finlayson, J., Di Nardo, A., \& 547 McInnes, C.J. (2016). Host-pathogen dynamics of squirrelpox virus infection in red squirrels 548 (Sciurus vulgaris). Veterinary Microbiology, 182, 18-27. doi: 10.1016/j.vetmic.2015.10.012.

549 Foreyt, W. J. (2011). Veterinary parasitology reference manual (5th ed.). Iowa, USA: Wiley550 Blackwell.

551 Gelman, A., \& Rubin, D. B. (1992). Inference from iterative simulation using multiple sequences. 
553 Geweke, J. (1992). Evaluating the accuracy of sampling-based approaches to the calculation of 554 posterior moments. In J. M. Bernardo, A. P. Berger, A. P. Dawid, \& A. F. M. Smith (Eds.) Bayesian 555 Statistics 4, pp. 169-193. Oxford University Press, Oxford. doi: 1176289

556 Goedknegt, M. A., Feis, M. E., Wegner, K. M., Luttikhuizen, P. C., Buschbaum, C., Camphuysen, 557 K. C., ..., Thieltges, D. W. (2016). Parasites and marine invasions: Ecological and evolutionary 558 perspectives. Journal of Sea Research, 113, 11-27. doi: 10.1016/j.seares.2015.12.003

559 Gurnell, J., Wauters, L. A., Lurz, P. W., \& Tosi, G. (2004). Alien species and interspecific 560 competition: effects of introduced eastern grey squirrels on red squirrel population dynamics. 561 Journal of Animal Ecology, 73, 26-35. doi:10.1111/j.1365-2656.2004.00791.x

Hadfield, J. D. (2010). MCMC Methods for Multi-Response Generalized Linear Mixed Models: The MCMCglmm R Package. Journal of Statistical Software, 33, 1-22. doi:10.18637/jss.v033.i02. Hänninen, L., \& Pastell, M. (2009). CowLog: open-source software for coding behaviors from digital video. Behavior Research Methods, 41, 472-476. doi:10.3758\%2FBRM.41.2.472 Hatcher, M. J., Dick, J. T. A., \& Dunn, A. M. (2006). How parasites affect interactions between competitors and predators. Ecology Letters, 9, 1253-1271. doi:10.1111/j.1461-0248.2006.00964.x

Hawley, D. M., Etienne, R.S., Ezenwa, V. O., \& Jolles, A. E. (2011). Does animal behavior underlie covariation between hosts' exposure to infectious agents and susceptibility to infection?

570 Implications for disease dynamics. Integrative and Comparative Biology, 51, 528-539.

571 doi:10.1093/icb/icr062

572 Henrichs, B., Oosthuizen, M. C., Troskie, M., Gorsich, E., Gondhalekar, C., Beechler, B. R., 573 Ezenwa, V. O., \& Jolles, A. E. (2016). Within guild co-infections influence parasite community 
membership: a longitudinal study in African Buffalo. Journal of Animal Ecology, 85, 1025-1034. doi:10.1111/1365-2656.12535

Hicks, O., Burthe, S.J., Daunt, F., Newell, M., Butler, A., Ito, M., Sato, K., \& Green, J.A. (2018).

The energetic cost of parasitism in a wild population. Proceedings of the Royal Society of London B: Biological Sciences, 285, 20180489. doi: 10.1098/rspb.2018.0489

Hofmannová, L., Romeo, C., Štohanzlová, L., Jirsová, D., Mazzamuto, M.V., Wauters, L.A., Ferrari, N., \& Modrý, D. (2016). Diversity and host specificity of coccidia (Apicomplexa: Eimeriidae) in native and introduced squirrel species. European journal of protistology, 56, 1-14. doi: 10.1016/j.ejop.2016.04.008

Kelly, D.W., Paterson, R.A., Townsend, C.R., Poulin, R., \& Tompkins, D. M. (2009). Parasite spillback: a neglected concept in invasion ecology? Ecology, 90, 2047-2056. doi:10.1890/081085.1

Kekäläinen, J., Lai, Y-T., Vainikka, A., Sirkka, I., \& Kortet R. (2014). Do brain parasites alter host personality? - Experimental study in minnows. Behavioral Ecology and Sociobiology, 68, 197-204.

Kortet, R., Hedrick, A. V., \& Vainikka, A. (2010). Parasitism, predation and the evolution of animal personalities. Ecology Letters, 13, 1449-1458. doi:10.1111/j.1461-0248.2010.01536.x

Levine, J. M., Bascompte, J., Adler, P. B., \& Allesina, S. (2017). Beyond pairwise mechanisms of species coexistence in complex communities. Nature, 546, 56-64. doi:10.1038/nature22898 Lymbery, A. J., Morine, M., Gholipour Kanani, H., Beatty, S. J., \& Morgan, D. L. (2014). Coinvaders: The effects of alien parasites on native hosts. International Journal for Parasitology: Parasites and Wildlife, 3, 171-177. doi:10.1016/j.ijppaw.2014.04.002 
directions. Trends in Ecology \& Evolution, 30, 199-206. doi:10.1016/j.tree.2015.01.010.

Mazzamuto, M. V., Cremonesi, G., Santicchia, F., Preatoni, D. G., Martinoli, A., \& Wauters, L. A. (2018). Rodents in the arena: a critical evaluation of methods measuring personality traits. Ethology, Ecology and Evolution, 31, 38-58. doi:10.1080/03949370.2018.1488768

Paterson, S., \& Viney, M.E. (2002). Host immune responses are necessary for density dependence in nematode infections. Parasitology, 125, 283-292. doi: 10.1017/s0031182002002056

Patterson, L.D., \& Schulte-Hostedde, A.I. (2011). Behavioural correlates of parasitism and reproductive success in male eastern chipmunks, Tamias striatus. Animal Behaviour, 81, 1129-1137. doi:10.1016/j.anbehav.2011.02.016

Petkova, I., Abbey-Lee, R. N., \& Løvlie, H. (2018). Parasite infection and host personality: Glugeainfected three-spined sticklebacks are more social. Behavioral Ecology and Sociobiology, 72, 173. doi:10.1007/s00265-018-2586-3

Poirotte, C., Kappeler, P. M., Ngoubangoye, B., Bourgeois, S., Moussodji, M., \& Charpentier, M. J.

E. (2016). Morbid attraction to leopard urine in Toxoplasma-infected chimpanzees. Current Biology, 26, R83-R101. doi:10.1016/j.cub.2015.12.020

611 Poulin, R. (2013). Parasite manipulation of host personality and behavioural syndromes. The 612 Journal of Experimental Biology, 216, 18-26. doi:10.1242/jeb.073353

613 Power, A.G., \& Mitchell, C.E. (2004). Pathogen spillover in disease epidemics. The American 614 Naturalist, 164(5), S79-S89. doi:10.1086/424610

615 R Core Team (2019). R: A language and environment for statistical computing. R Foundation for 616 Statistical Computing, Vienna, Austria. URL https://www.R-project.org/

617 Réale, D., Reader, S. M., Sol, D., McDougall, P. T., \& Dingemanse, N. J. (2007). Integrating animal 
temperament within ecology and evolution. Biological Reviews, 82, 291-318. doi:10.1111/j.1469185X.2007.00010.X

Rhoades, O. K., Best, R. J., \& Stachowicz, J. J. (2018). Assessing Feeding Preferences of a Consumer Guild: Partitioning Variation Among versus Within Species. The American Naturalist, 192, 287-300. doi:10.1086/698325

Romeo, C., Pisanu, B., Ferrari, N., Basset, F., Tillon, L., Wauters, L. A., Martinoli, A., Saino, N., \& Chapuis, J.-L. (2013). Macroparasite community of the Eurasian red squirrel (Sciurus vulgaris): poor species richness and diversity. Parasitology Research, 112, 3527-3536. doi:10.1007/s00436013-3535-8

Romeo, C., Wauters, L. A., Ferrari, N., Lanfranchi, P., Martinoli, A., Pisanu, B., Preatoni, D. G., \& Saino, N. (2014a). Macroparasite fauna of alien grey squirrels (Sciurus carolinensis): Composition, variability and implications for native species. PloS ONE, 9, e88002. doi:10.1371/journal.pone.0088002

Romeo, C., Wauters, L. A., Cauchie, S., Martinoli, A., Matthysen, E., Saino, N., \& Ferrari, N. (2014b). Faecal egg counts from field experiment reveal density dependence in helminth fecundity: Strongyloides robustus infecting grey squirrels (Sciurus carolinensis). Parasitology Research, 113, 3403-3408. doi:10.1007/s00436-014-4005-7

Romeo, C., Ferrari, N., Lanfranchi, P., Saino, N., Santicchia, F., Martinoli, A., \& Wauters, L. A. (2015). Biodiversity threats from outside to inside: effects of alien grey squirrel (Sciurus carolinensis) on helminth community of native red squirrel (Sciurus vulgaris). Parasitology Research, 114, 2621-2628. doi:10.1007/s00436-015-4466-3

Romero, L.M. (2004). Physiological stress in ecology: lessons from biomedical research Trends in Ecology \& Evolution, 19, 249-255. doi: 10.1016/j.tree.2004.03.008 
641 Rothenburger, J.L., Himsworth, C.G., Nemeth, N.M., Pearl, D.L., Treuting, P.M., \& Jardine, J.M.

642 (2019). The devil is in the details—-Host disease and co

pathogen carriage in Norway rats (Rattus norvegicus). Zoonoses and Public Health, 66, 622-635.

Santicchia, F., Romeo, C., Martinoli, A., Lanfranchi, P., Wauters, L.A., \& Ferrari, N. (2015). Effects

of habitat quality on parasite abundance: do forest fragmentation and food availability affect helminth infection in the Eurasian red squirrel? Journal of Zoology, London, 296, 38-44. doi: 10.1111/jzo.12215

Santicchia, F., Dantzer, B., van Kesteren, F., Palme, R., Martinoli, A., Ferrari, N., \& Wauters, L.A. (2018). Stress in biological invasions: introduced invasive grey squirrels increase physiological stress in native Eurasian red squirrels. Journal of Animal Ecology, 87, 1342-1352. doi:10.1111/1365-2656.12853

Santicchia, F., Romeo, C., Ferrari, N., Matthysen, E., Vanlauwe, L., Wauters, L. A., \& Martinoli, A. (2019). The price of being bold? Relationship between personality and endoparasitic infection in a tree squirrel. Mammalian Biology, 97, 1-8. doi:10.1016/j.mambio.2019.04.007

Sih, A., Cote, J., Evans, M., Fogarty, S., \& Pruitt, J. (2012). Ecological implications of behavioural syndromes. Ecology Letters, 15, 278-289. doi:10.1016/j.anbehav.2017.09.008 immunity and parasite life histories in primates and oxyurid parasites. Proceedings of the Royal Society of London B: Biological Sciences, 270, doi: 10.1098/rspb.2003.2536

Strauss, A., White, A., \& Boots, M. (2012). Invading with biological weapons: the importance of disease-mediated invasions. Functional Ecology, 26, 1249-1261. doi: 10.1111/1365-2435.12011 
665 Tompkins, D.M., Sainsbury, A.W., Nettleton, P., Buxton, D., \& Gurnell, J. (2002). Parapoxvirus 666 causes a deleterious disease in red squirrels associated with UK population declines. Proceedings of the Royal Society of London B: Biological Sciences, 269, 529-533. doi: 10.1098/rspb.2001.1897

668 Tompkins, D.M., White, A.R., \& Boots, M. (2003). Ecological replacement of native red squirrels 669 by invasive greys driven by disease. Ecology Letters, 6, 189-196. doi:10.1046/j.1461$670 \quad$ 0248.2003.00417.x

671 VanderWaal, K. L., \& Ezenwa, V. O. (2016). Heterogeneity in pathogen transmission: mechanisms 672 and methodology. Functional Ecology, 30, 1606-1622. doi:10.1111/1365-2435.12645

673 Wauters, L. A., \& Dhondt, A. A. (1989). Body weight, longevity and reproductive success in red 674 squirrels (Sciurus vulgaris). Journal of Animal Ecology, 58, 637-651. doi:10.2307/4853

675 Wauters, L. A., \& Dhondt, A. A. (1992). Spacing behaviour of red squirrels, Sciurus vulgaris: 676 variation between habitats and the sexes. Animal Behaviour, 43, 297-311. doi: 10.1016/S0003677 3472(05)80225-8

678 Wauters, L., Tosi, G., \& Gurnell, J. (2002a). Interspecific competition in tree squirrels: do 679 introduced grey squirrels (Sciurus carolinensis) deplete tree seeds hoarded by red squirrels (S. 680 vulgaris)? Behavioral Ecology and Sociobiology, 51, 360-367. doi:10.1007/s00265-001-0446-y

Wauters, L., Gurnell, J., Martinoli, A., \& Tosi, G. (2002b). Interspecific competition between native 682 Eurasian red squirrels and alien grey squirrels: does resource partitioning occur? Behavioral 683 Ecology and Sociobiology, 52, 332-341. doi:10.1007/s00265-002-0516-9

684 Wauters, L. A., Vermeulen, M., Van Dongen, S., Bertolino, S., Molinari, A., Tosi, G., \& Matthysen, 685 E. (2007). Effects of spatio-temporal variation in food supply on red squirrel Sciurus vulgaris body 
686 size and body mass and its consequences for some fitness components. Ecography, 30, 51-65.

687 doi:10.1111/j.2006.0906-7590.04646.x

688 Wauters, L. A., Mazzamuto, M. V., Santicchia, F., Van Dongen, S., Preatoni, D. G., \& Martinoli, A.

689 (2019). Interspecific competition affects the expression of personality traits in natural populations.

690 Scientific Reports, 9, 11189. doi:10.1038/s41598-019-47694-4

691 Wilson, A.J., Réale, D., Clements, M.N., Morrissey, M.M., Postma, E., Walling, C.A., Kruuk, 692 L.E.B., \& Nussey, D.H. (2010). An ecologist's guide to the animal model. Journal of Animal 693 Ecology, 79, 13-26.

694 
695 Table 1. The squareroot transformed proportions of time red squirrels were engaged in behaviours 696 related to the different personality traits defined by the expert-based approach during OFT and MIS.

697 Data grouped by situation (study sites with only red squirrels = red-only; study sites with both red 698 and grey squirrels = red-grey). Repeatability $(\mathrm{R})$ estimated with the MCMCglmm model (see 699 methods).

\begin{tabular}{|c|c|c|c|c|c|c|c|}
\hline \multirow{2}{*}{\multicolumn{2}{|c|}{ Personality trait }} & \multicolumn{2}{|c|}{ red-only $(n=171)$} & \multicolumn{2}{|c|}{ red-grey $(n=152)$} & \multicolumn{2}{|c|}{ Repeatability } \\
\hline & & Mean & $S D$ & Mean & $S D$ & $\mathrm{R}$ & $95 \% C I$ \\
\hline \multirow{3}{*}{ OFT } & Activity & 0.57 & 0.16 & 0.52 & 0.17 & 0.39 & $0.23-0.52$ \\
\hline & Shyness & 0.73 & 0.17 & 0.77 & 0.17 & 0.41 & $0.24-0.58$ \\
\hline & Exploration & 0.21 & 0.10 & 0.20 & 0.11 & 0.05 & $0.01-0.29$ \\
\hline \multirow{5}{*}{ MIS } & Sociability & 0.18 & 0.28 & 0.36 & 0.36 & 0.20 & $0.04-0.34$ \\
\hline & Avoidance & 0.69 & 0.31 & 0.60 & 0.36 & 0.10 & $0.002-0.25$ \\
\hline & Alert & 0.30 & 0.19 & 0.27 & 0.17 & 0.02 & $0.004-0.18$ \\
\hline & Activity-exploration & 0.37 & 0.20 & 0.31 & 0.18 & 0.46 & $0.31-0.61$ \\
\hline & Social score $^{1}$ & -2.01 & 1.17 & -1.61 & 1.33 & 0.27 & $0.12-0.41$ \\
\hline
\end{tabular}

$700{ }^{1}$ Calculated with formula social score = log-transformed [(sociability score + (1-avoidance score) $\left.) / 2\right]$ 
Table 2. Correlations (95\% credibility intervals between brackets) between the dependent variables derived from the MCMCglmm models by area-type (red-only or red-grey), and the differences between posterior slopes of the correlation estimates for red-only and red-grey area-type (red-only red-grey: mean $\pm S D$ and $95 \% C I)$. T. sciuri is estimated probability of infection by $T$. sciuri; $S$. robustus is estimated probability of infection by S. robustus. Estimates of the between-individual and within-individual variances for the three personality traits in the red-only and the red-grey sites and the calculated differences between sites are detailed in the Supporting Information (Table S6).

709

\begin{tabular}{|c|c|c|c|}
\hline Variables & Red-only & Red-grey & Difference \\
\hline Activity - social & $0.86(0.60-0.99)$ & $0.20(-0.44-0.82)$ & $0.66 \pm 0.35(-0.004-1.39)$ \\
\hline Activity - Activity-exploration & $0.88(0.66-0.99)$ & $0.72(0.32-0.99)$ & $0.16 \pm 0.23(-0.23-0.72)$ \\
\hline Social - Activity-exploration & $0.85(0.56-0.99)$ & $0.35(-0.28-0.98)$ & $0.48 \pm 0.38(-0.16-1.32)$ \\
\hline Activity $-T$. sciuri & $0.20(-0.26-0.64)$ & $-0.69(-0.99--0.33)$ & $0.89 \pm 0.30(0.26-1.44)$ \\
\hline Activity-exploration - T. sciuri & $0.08(-0.51-0.67)$ & $-0.30(-0.79-0.22)$ & $0.37 \pm 0.40(-0.42-1.15)$ \\
\hline Social - T. sciuri & $0.17(-0.55-0.88)$ & $0.07(-0.45-0.59)$ & $0.10 \pm 0.46(-0.83-0.96)$ \\
\hline Activity - S. robustus ${ }^{1}$ & & $-0.66(-0.99--0.004)$ & \\
\hline Activity-exploration - S. robustus ${ }^{1}$ & & $-0.52(-0.99-0.21)$ & \\
\hline Social - S. robustus ${ }^{1}$ & & $-0.27(-0.99-0.53)$ & \\
\hline T. sciuri-S. robustus ${ }^{1}$ & & $0.53(-0.19-1.00)$ & \\
\hline
\end{tabular}

${ }^{1}$ Relationships only occurring in Red-grey sites. Significant results in bold. 
713 FIGURE 1 Difference in the squareroot transformed values of proportion activity expressed during

714 OFT ( $\Delta$ activity; see methods and results for details) in two groups of red squirrels. In group 1,

715 animals were not infected during the first activity measure, but infected during the second measure.

716 In group 2, animals were uninfected at both measures of activity. Boxplots show median (horizontal

717 line), mean (black diamond) and $1^{\text {st }}(25 \%)$ and $3^{\text {rd }}(75 \%)$ quartiles.

719 FIGURE 2 Relationship between intensity of infection by S. robustus, estimated using faecal egg 720 counts (FEC), and a standardized score of amount of activity expressed by red squirrels during the 721 OFT for: a) red squirrels also infected by T. sciuri; b) red squirrels not infected by T. sciuri.

722 Observed values (grey dots) and values predicted by the model (line). Grey band indicates 95\% CI. 